\title{
STABILITY EVALUATION OF MASONRY RETAINING WALLS BASED ON THE DEFORMATION RATIO OF THE MAXIMUM HORIZONTAL DISPLACEMENT TO THE HEIGHT
}

\author{
TSUYOSHI TAKAYANAGI \& OTA NAOYUKI \\ Geotechnical Hazard \& Risk Mitigation Disaster Prevention Technology Div, Railway Technical Research \\ Institute, Japan.
}

\begin{abstract}
Many masonry retaining walls which were constructed by using square pyramidal stones over 100 years ago exist on cutting-slopes in Japanese railways. In these walls, there are some arch-deformed walls that resulted from receiving external force like an earth pressure or a seismic shaking. These deformed walls have a relatively high risk of collapse in case of receiving the large external force. But the relationship between the deformation amount and the stability of the wall is unclear. For this reason, this study evaluates the threshold deformation ratio of the maximum horizontal displacement of the wall to its height for discriminating unstable masonry retaining walls by modelling tests. In the modelling tests, we collapsed two meter-tall masonry retaining walls which are composed of $200 \mathrm{~mm} \times 200$ $\mathrm{mm} \times 334 \mathrm{~mm}$ - square pyramidal stones by vertical loading applied at the top of slope, and measured earth pressure and horizontal displacement of the wall. As a result of the test, the masonry retaining wall was deformed over $4 \%$ deformation ratio by receiving the limit earth pressure against the bearing capacity. This study made it clear that old masonry retaining walls existing in Japanese railways which are deformed over $4 \%$ deformation ratio should be judged as unstable. Furthermore we developed simple reinforcement works for the deformed walls and confirmed the deformation prevention effect of those works by the modelling test.
\end{abstract}

Keywords: deformation ratio, earth pressure, masonry retaining walls, modeling test, reinforcement work.

\section{INTRODUCTION}

Many masonry retaining walls that were constructed by using square pyramidal stones over 100 years ago exist on cutting-slopes in Japanese railways. In these masonry retaining walls, there are some arch-deformed walls which resulted from receiving external force like an earth pressure or a seismic shaking, as shown in Fig. 1. These deformed walls have a relatively high risk of collapse in case of receiving the large external force. The collapse becomes a threat to the train's safety. For these reasons, Japanese railway companies make a visual inspection of earth structures like a masonry retaining wall every two years and look out extraordinary deformation. But the relationship between the deformation amount and the stability of the wall is unclear up to now.

According to the previous study about Japanese castles, deformed stonewalls whose ratio of the maximum horizontal displacement to its height is over $6 \%$ are experientially judged as unstable [1]. But stones used in railway's masonry retaining walls are apprecia- 


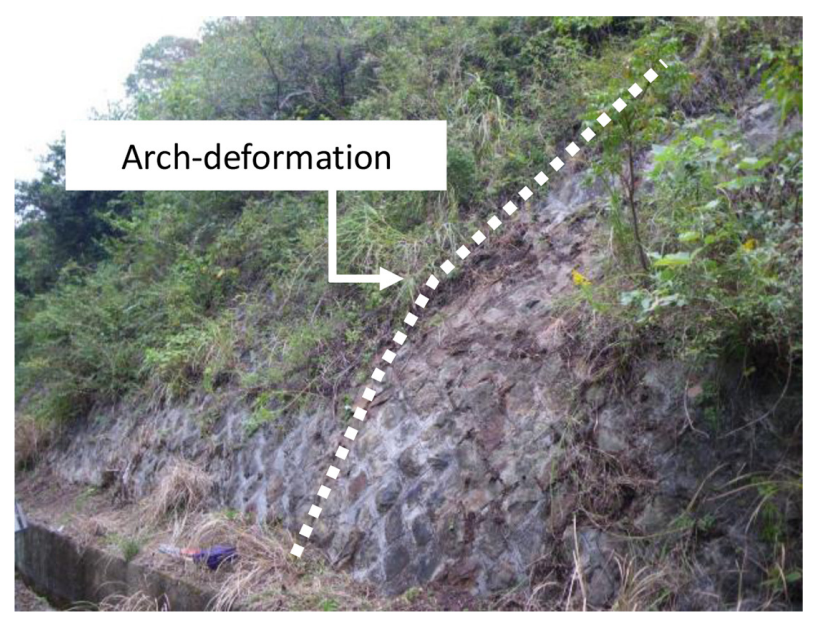

Figure 1: Example of an arch-deformed masonry retaining wall.

bly smaller than the castle's ones. The threshold deformation ratio for railway's masonry retaining walls should be evaluated separately. For this reason, this study evaluates the threshold deformation ratio for masonry retaining walls constructed on an earth slope by a modeling test. Furthermore we developed simple reinforcement works by using rock-bolts, angle steels or shotcrete for the deformed walls, and confirmed the effectiveness of the works by the modeling test.

\section{METHOD OF MODELLING TEST}

\subsection{Equipment}

In this modeling test, we applied load vertically at the top of masonry retaining wall which was constructed on model slope by using square pyramidal stones. By the vertical loading, an earth pressure was applied to masonry retaining wall, and the wall was deformed. In some case, the wall collapsed completely by the loading. The equipment of modeling test is shown in Fig. 2. In this test, we fixed the size of the model as follows. The height of masonry retaining wall is $2,144 \mathrm{~mm}$; the width, $1,200 \mathrm{~mm}$; and the inclination of the front face, $70^{\circ}$. Pyramidal stones used for the modeling test were made from concrete by referring to stones that are generally used in Japanese railways. The size of pyramidal concrete-block used in this test was fixed as follows as shown in Fig. 3; front side length is $200 \mathrm{~mm}$; back side length, $120 \mathrm{~mm}$; and lateral side length, $334 \mathrm{~mm}$. The weight of each model stone is $230 \mathrm{~N}$. We built masonry retaining wall by heaping up these blocks flatly step by step. The gravel layer behind the masonry retaining wall was built to $150 \mathrm{~mm}$ thickness by using coast gravel whose average grain diameter is $30 \mathrm{~mm}$. Model slope consisted of Inagi Sand which is one of the Japanese local sand used as an earth structure material.

\subsection{Construction procedure}

The construction procedure of the masonry retaining wall is as follows. Firstly, we built an outside framed box by using steel plates and steel beams, and set a sliding plate aslant facing the bottom corner of the framed box. Secondly, we put the first layer of the concrete blocks 


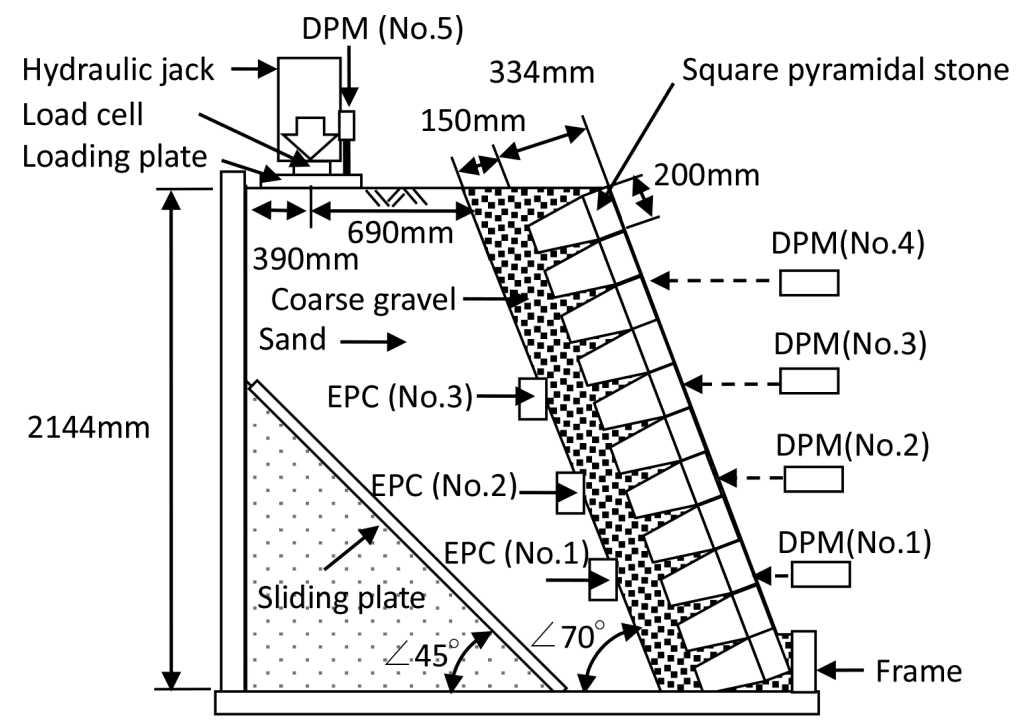

Figure 2: Side view of equipments of modelling test.

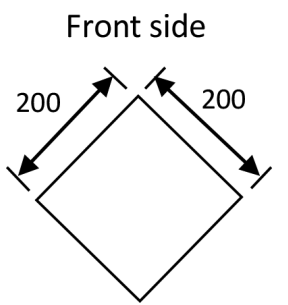

Lateral side

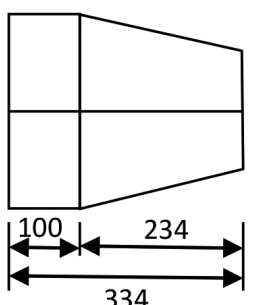

Back side

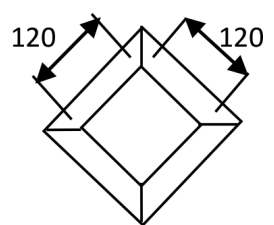

Unit: $\mathrm{mm}$

Figure 3: Size of square pyramidal stone.

on the bottom of the framed box, and put dry coast gravel and unsaturated sand into the framed box behind the blocks for constructing $250 \mathrm{~mm}$-tall sand layer. Then water content ' $w$ ' of the sand was adjusted so as to be the optimum water content ' $w_{\mathrm{opt}}$ '. The optimum water content is $18 \%$. Thirdly, we compacted sand layer dynamically and set several sensors in the model slope. Thus, we laid the layer of concrete- blocks, gravel, and sand. Finally, we constructed 2,144 mm-tall masonry retaining wall by repeating the above procedures from the second to the third, and put a loading square plate whose side length is $1,100 \mathrm{~mm}$ and 500 $\mathrm{mm}$ at the top of model slope. Then ' $N_{\mathrm{d}}$ ' resistance value of the sand layer measured by simple dynamic cone penetration test [2] was from 5 to 10.

\subsection{Loading procedure}

We applied an earth pressure to the masonry retaining wall through vertical loading at the top of the slope in each test case. Then a hydraulic jack with the maximum loading capacity of $200 \mathrm{kN}$ was used for the loading. The vertical loading was conducted step-by-step by repeating load and un-load. 
Table 1: Test condition.

\begin{tabular}{lcccl}
\hline & $\begin{array}{c}\text { Dry density [sand] } \\
\rho_{\mathrm{d}}\left(\mathrm{g} / \mathrm{cm}^{3}\right)\end{array}$ & $\begin{array}{c}\text { Water content [sand] } \\
w(\%)\end{array}$ & $\begin{array}{c}\text { Water level } \\
W_{L}(\mathrm{~m})\end{array}$ & Reinforcement \\
\hline Case1 & 1.55 & 19.95 & 0 & None \\
Case2 & 1.55 & 18.23 & 0 & None \\
Case3 & 1.50 & 17.60 & 1.2 & None \\
Case4 & 1.48 & 18.92 & 0 & Type1 \\
Case5 & 1.52 & 18.37 & 0 & Type2 \\
\hline
\end{tabular}

\subsection{Test condition}

Each test condition is shown in Table 1. In Case1, the loading was stopped on the way due to the equipment's trouble. Accordingly, the test of the same condition as Case1 was conducted in Case2. For studying about the influence of water behind the wall, we tried to make a test under other ground condition, namely the slope below the half height of the wall was water-saturated in Case 3 . We also confirmed the effect of reinforcement work for the deformed masonry retaining walls by applying an earth pressure to the reinforced wall in Case 4 and Case5. Details of each reinforcement work are explained in the section 3.2.1.

\subsection{Measurement components}

Major measurement items of this modeling test are an earth pressure applied to masonry retaining wall and displacement of the wall from the initial condition. Measurement points of earth pressure by EPC 'Earth Pressure Cell' are located at $547 \mathrm{~mm}, 922 \mathrm{~mm}$ and 1,298 mm-height of the wall (three points). Measurement points of displacement of wall by DPM 'Displacement meter' are located at $547 \mathrm{~mm}, 922 \mathrm{~mm}, 1,298 \mathrm{~mm}$ and 1,674 mm-height of the wall (four points). Furthermore, we measured a vertical load at the top of the slope and the settlement of loading plate.

\section{RESULTS OF MODELLING TEST}

\subsection{Unreinforced masonry retaining walls [Case1 Case3]}

It has been confirmed that many actual deformed masonry retaining walls which are arch-deformed by receiving external force like an earth pressure. In the modelling test, we could also reproduce the arch-deformed masonry retaining wall by the experiment described in Chapter2. The frontal shape of the deformed masonry retaining wall viewed from the lateral side for each loading condition in Case2 is shown in Fig. 4. As shown in Fig. 4, the deformation of the wall progressed with the increment of loading. This chapter focuses on the relationship between the earth pressure applied to the wall and the displacement of the wall examined based on the results of the modelling test. Then the deformation ratio of the maximum horizontal displacement of the wall to its height is adapted as one of deformation index. Elements for defining the deformation ratio are shown in Fig. 5, and the definition of the ratio is given by eqn (1). 


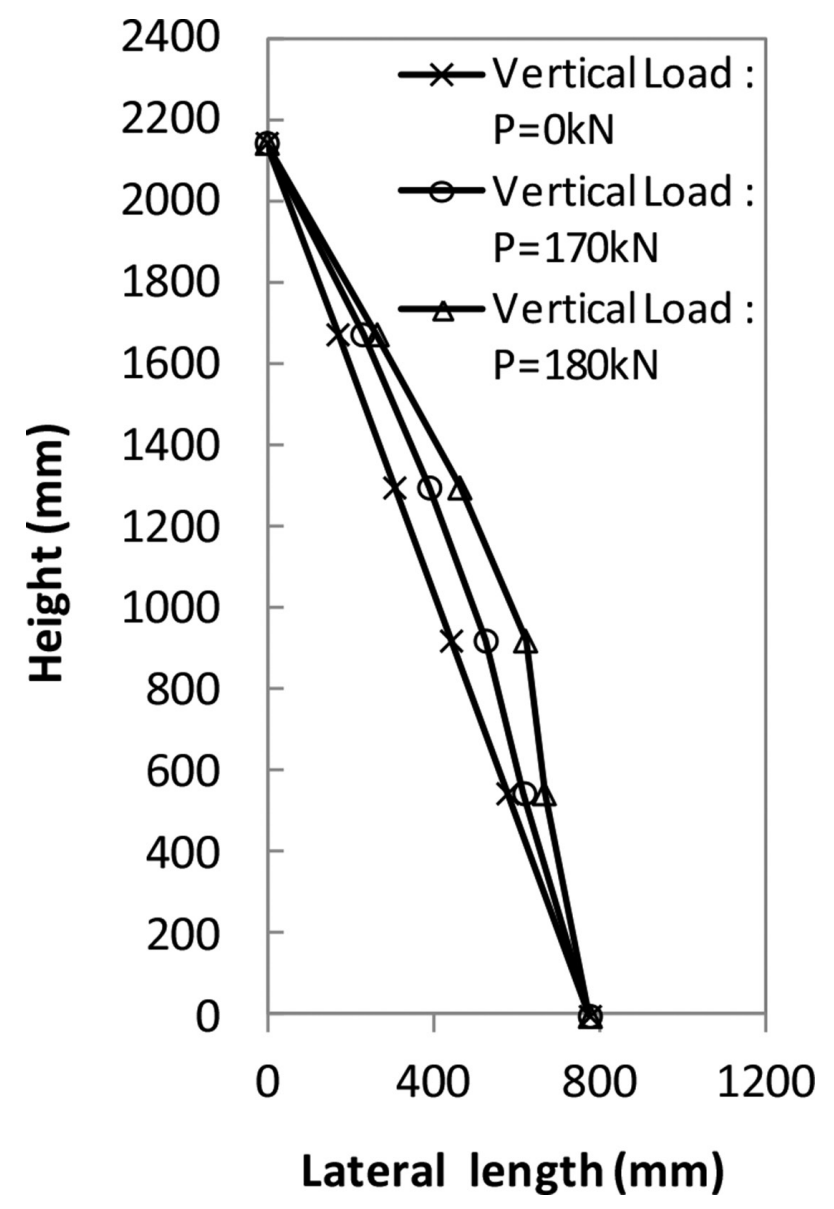

Figure 4: Lateral view of wall's shape in Case2.

\subsubsection{Behaviour of individual stone}

Relationships between the earth pressure and the displacement at the respective measurement points, e.g. the relationship between EPC (no.1) and DPM (no.1), in Case2 are shown in Fig. 7. These relationships show behaviour of each individual pyramidal stone fitted with EPC and DPM by receiving an earth pressure. Comparison of the results of each stone's behaviour is as follows. As for the stone attached EPC (no.1) at height of $547 \mathrm{~mm}$, the displacement of the stone is increasing with the increment of earth pressure, and the earth pressure reaches the peak at the displacement of $50 \mathrm{~mm}$. After the peak, the earth pressure has a trend to decrease. But such clear peak cannot be recognized with respect to behaviours of other stones. Thus behaviour of individual stones, namely the relationship between the earth pressure and the displacement for individual stones shows large variations.

\subsubsection{Behaviour of masonry retaining wall}

Next, we discuss the relationship between total force of earth pressure applied to the wall and deformation ratio in Case 1, Case 2 and Case 3 . The total force can be calculated by multiplying average earth pressure by frontal area of the wall. Those relationships are shown in Fig. 8. 


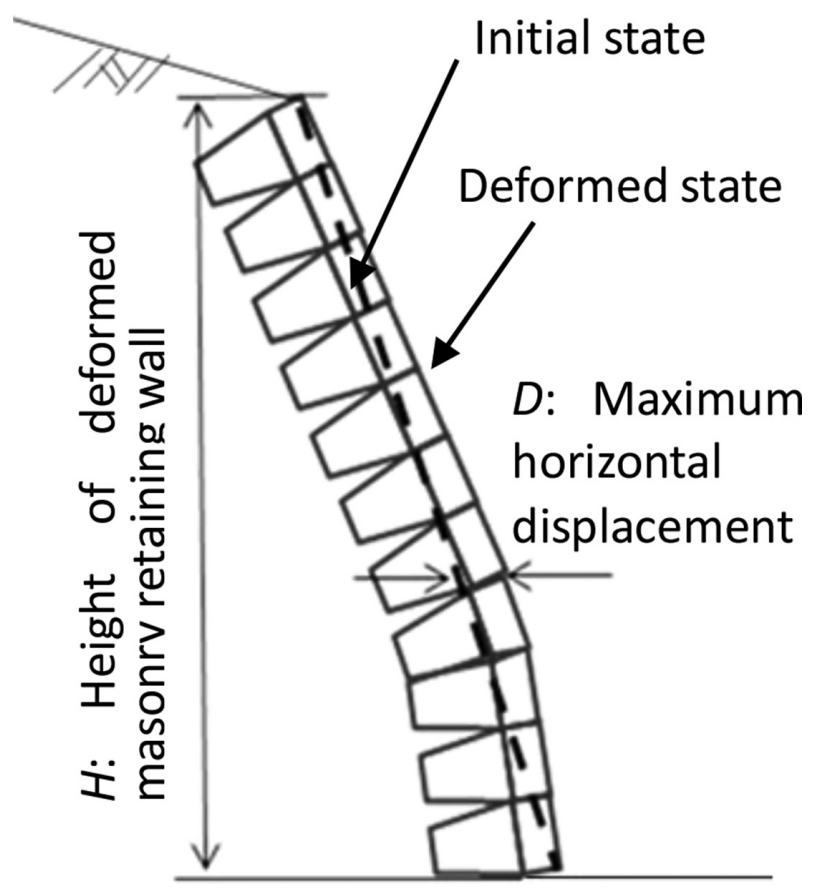

Figure 5: Elements for defining deformation ratio.

Deformation ratio of each case is increases with an increment of the total force, and the total force reaches its peak at the time when the deformation ratio reaches to the certain value. After the peak, the total force a trend to decrease and the displacement increases rapidly. These tendencies are shown for every case. From these results of the modeling test, it was made clear that the masonry retaining wall which receives the limit earth pressure is likely to deform with 3 5\%-deformation ratio. These excessively deformed walls have a relatively high risk of collapse due to the external force. Therefore it is considered that old masonry retaining walls used generally in Japanese railways which is deformed over 4\%-deformation ratio, median value of $3 \%$ and $5 \%$, should be judged as unstable and some reinforcement work should be applied to that excessively deformed wall. But we should be also mindful of the fact that masonry retaining wall deformed with $4 \%$ deformation ratio did not collapse immediately, and it collapsed about $20 \%$ ratio. The threshold deformation ratio of $4 \%$ should be recognized as an early warning indicator for the maintenance.

$$
\delta=\frac{H}{D} \times 100
$$

$\delta$ : Deformation ratio, $\%$

$H$ : Height of deformed masonry retaining wall, mm

$D$ : Maximum horizontal displacement, $\mathrm{mm}$

\subsection{Reinforced masonry retaining wall [Case4, Case5]}

This section discusses simple reinforcement works for a deformed masonry retaining wall that is evaluated as unstable at the early stage. 

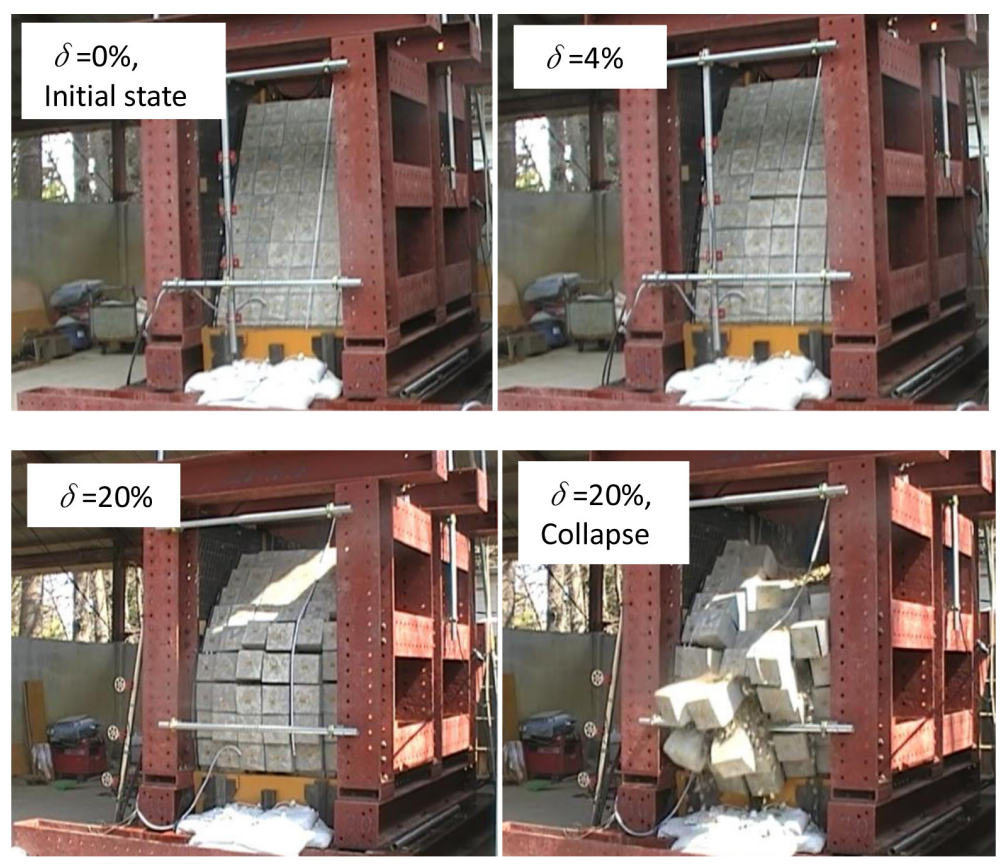

Figure 6: Collapse progression of masonry retaining wall in Case3.

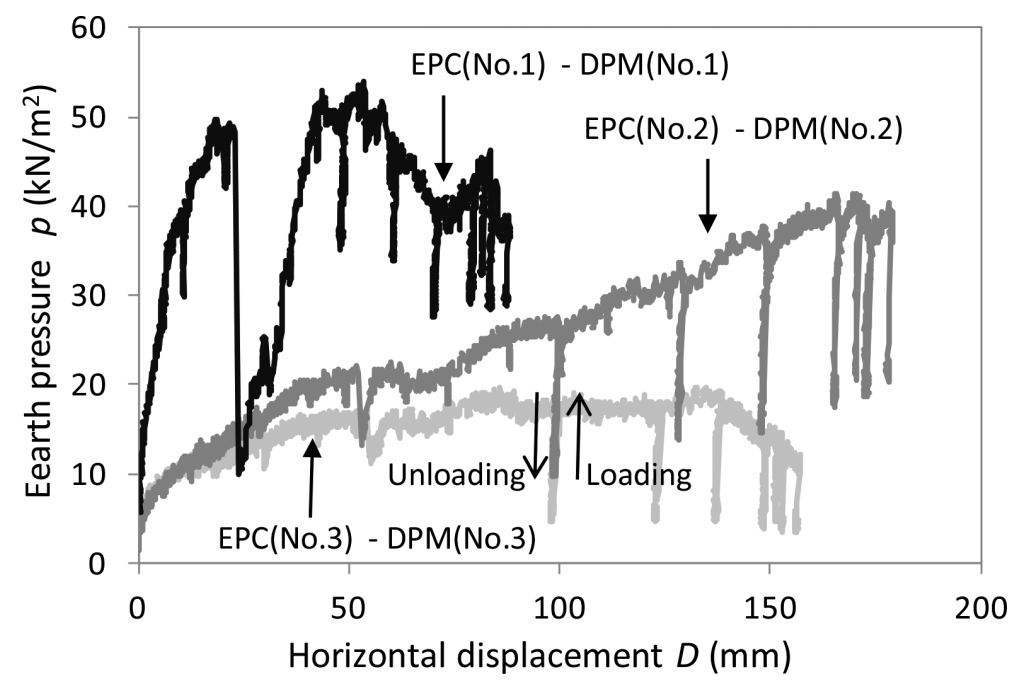

Figure 7: Relationship between earth pressure and horizontal displacement at each measurement point in Case2.

\subsubsection{Method of reinforcement}

We developed a simple reinforcement work Type1, inserting rock bolts into ground slope at the vertical interval of $1.5 \mathrm{~m}$ and attaching angle steels at the top of those rock bolts horizontally to clamp stones of masonry retaining wall. The side length and thickness of angle steel we used are $75 \mathrm{~mm}$ and $6 \mathrm{~mm}$, respectively. The lateral view of reinforcement work is shown 


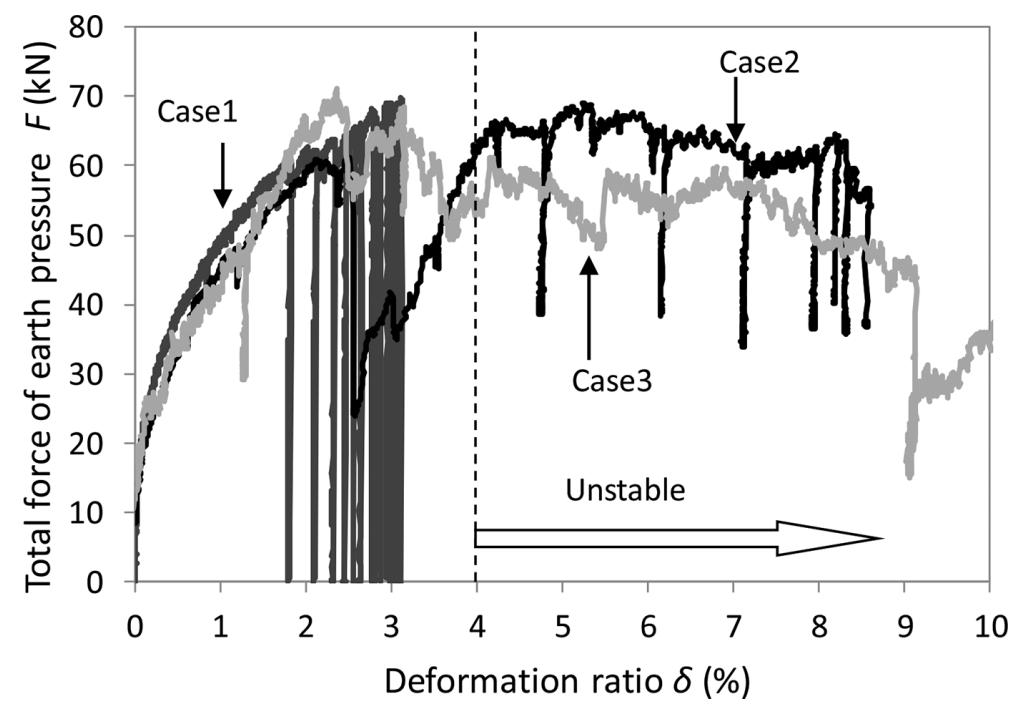

Figure 8: Relationship between total force of earth pressure and deformation ratio with respect to un-reinforcement wall.

in Fig. 9. This reinforcement work relies on the reaction force of the angle steels which is originally to be fixed at the top of the rock bolts, but insertion of those rock bolts to the ground slope was difficult by absence of specialized working machines in the modeling test. Accordingly, the reaction force of the angle steel is generated by fixing the angle to the framed box as a substitute way. In the reinforcement work of Type2, we sprayed shotcrete which was mixed with 1 vol\% polypropylene fiber, on the front surface of the wall in addition to the reinforcement work of Type1. The shotcrere has the compression strength of $29 \mathrm{~N} / \mathrm{mm}^{2}$, the elastic coefficient of $18,000 \mathrm{~N} / \mathrm{mm}^{2}$ after 28 days curing, and the thickness of about $5 \mathrm{~cm}$ and was overlaid on the front surface of the wall by hand working.

\subsubsection{Effect of reinforcement works}

The loading experiment to evaluate the effect to prevent the deformation of masonry retaining wall by those reinforcement works was conducted by the following the way explained in Chaper2. To examine the effect of those reinforcement works, a relationship between the vertical load at the top of slope and the maximum horizontal displacement of the masonry retaining wall are shown in Fig. 10. The masonry retaining wall reinforced by Type1 and Type2, could prevent large deformation as compared to the non-reinforced wall, and the reinforced masonry retaining walls could keep the deformation ratio under $4 \%$ for 200 $\mathrm{kN}$-vertical loading which generates the total force of earth pressure of about $60 \mathrm{kN}$. Reinforcement work Type 2 is more effective than type 1 in preventing deformation. But it should be noted that Type 2 caused disfigurement of the wall and the shotcrete was cracked around the center of wall by the earth pressure generated in this loading experiment. In this modeling test, it has been made clear that those reinforcement works have a certain effect of deformation prevention. But we could not confirm the maximum bearing capacity of those reinforced masonry retaining walls by making them collapse because a shortage of jack's capacity. However, we could confirm the effectiveness of those reinforcement works under the condition that the total force of earth pressure is under $60 \mathrm{kN}$. Therefore, it is considered that those reinforcement work should be applied under that condition. 


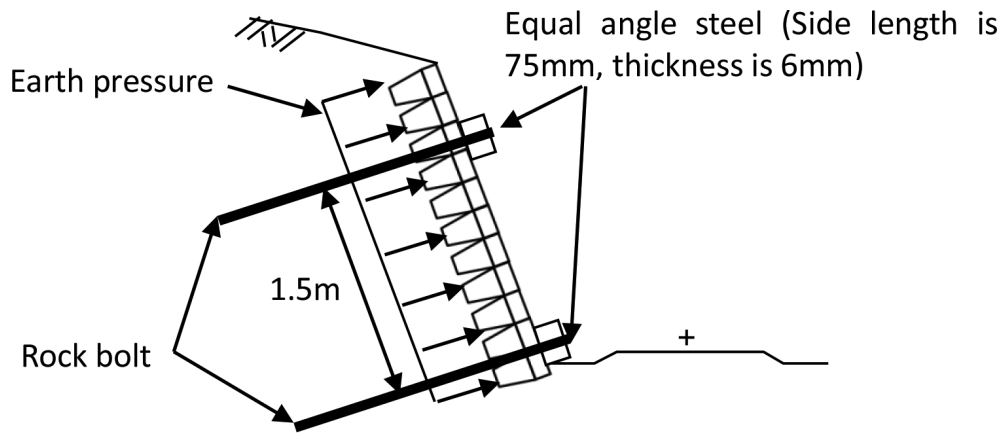

(a) Reinforcement work: Type1 (Case4)

Fiber mixed shotcrete (thickness is $50 \mathrm{~mm}$ )

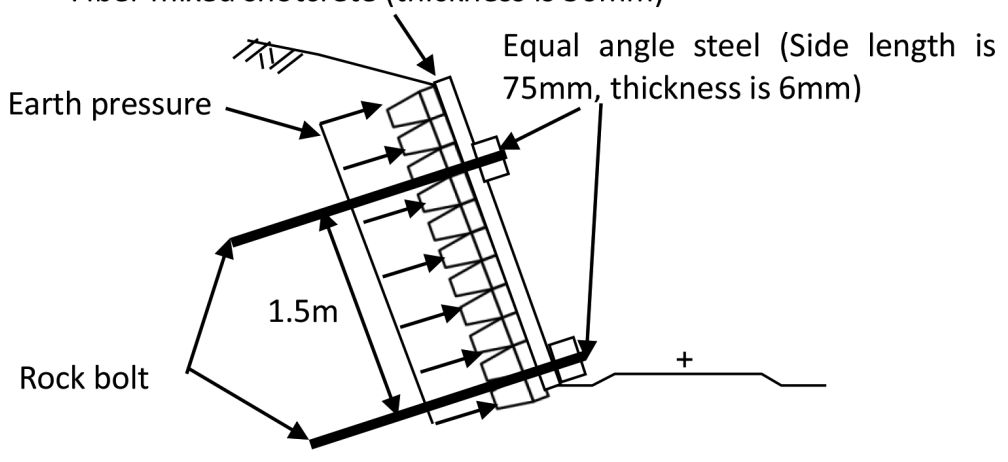

(b) Reinforcement work: Type2 (Case5)

Figure 9: Reinforcement work for masonry retaining wall.

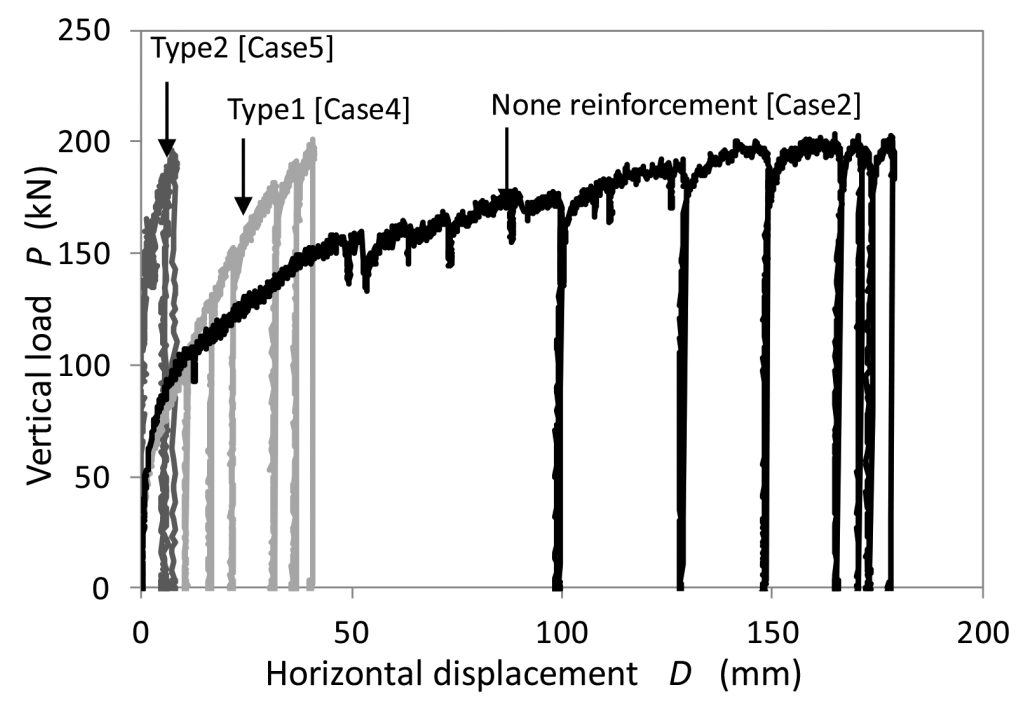

Figure 10: Relationships between vertical load and horizontal displacement. 


\section{CONCLUSIONS}

We conducted the modeling test to confirm the effectiveness of stability evaluation method for deformed masonry retaining walls based on the deformation ratio of the maximum horizontal displacement of the wall to its height. As a result of the test, the masonry retaining walls generally used in Japanese railway were deformed over 4\%-deformation ratio by receiving the limit earth pressure against the wall's bearing capacity. This study made it clear that the old masonry retaining walls which are deformed with more than $4 \%$-deformation ratio should be judged as unstable. We also developed the simple reinforcement works for the deformed walls and confirmed the deformation prevention effect of those works by the modeling test.

\section{REFERENCES}

[1] Amano, K., Nishida, K., Watanabe, T., Tamano, T. \& Hakamura, H., Historical and empirical study on osaka castle masonry wall at tokugawa period. Journal of Japan Society of Civil Engineers, 2000(660), pp. 101-110, 2000. http://dx.doi.org/10.2208/jscej.2000.660_101

[2] The Japanese geotechnical society, Method for Portable Dynamic Cone Penetration Test, Japanese geotechnical society standards, JGS1433, 2012. 